\title{
Structure of Professional Identity of Public Health Nurses Working for Governmental Agencies
}

\author{
Akiko Kanefuji, Hisae Nakatani \\ Division of Nursing Science, Graduate School of Biomedical \& Health Sciences, Hiroshima University, Hiroshima, Japan \\ Email: teccy@hiroshima-u.ac.jp
}

How to cite this paper: Kanefuji, A. and Nakatani, H. (2017) Structure of Professional Identity of Public Health Nurses Working for Governmental Agencies. Health, 9, 1776-1786.

https://doi.org/10.4236/health.2017.913129

Received: November 16, 2017

Accepted: December 8, 2017

Published: December 11, 2017

Copyright $\odot 2017$ by authors and Scientific Research Publishing Inc. This work is licensed under the Creative Commons Attribution International License (CC BY 4.0).

http://creativecommons.org/licenses/by/4.0/ Open Access

\begin{abstract}
Background: Public health nurses in Japan are nationally licensed professionals who act as members of local governments and provide services to local community residents. Public health nurses must establish their professional identity early on in order to deliver high quality public health services. However, the structure of their professional identity is not fully understood. Objectives: Our purpose was to investigate structures of professional identity of public health nurses working for governmental agencies, and to clarify characteristics of their professional identity. Methods: Questionnaire surveys were conducted on 670 PHNs working for local governmental agencies. The investigation items included measurement indices for professional identity of PHNs, basic attributes, and scales which reflect aspects of self-respect. After analyzing the investigated items, we conducted exploratory factor analysis. Also we named extracted factors, and investigated reliability and appropriateness. Relationships with the attributes or self-respect aspects were also analyzed. Results: Of 350 respondents (52.2\%), 309 effective answers (effective answer ratio: $88.2 \%$ ) were analyzed. Item and factor analyses identified 12 items, which were categorized into 3 factors: "intention to develop professionally", "confidence in own abilities", and "occupational affinity". Scales of self-respect aspects and the index for professional identity showed positive correlation. The coefficient for all 12 items was 0.89. Significant difference with the attributes were noted for "age", "years of experience as PHNs", and "number of PHN in the workplace". Conclusion: Professional identity of $\mathrm{PHN}$ is found to be consisted of 3 factors.
\end{abstract}

\section{Keywords}

Professional Identity, Public Health Nurses, Structure 


\section{Introduction}

Public health nurses (=PHNs) in Japan are nationally licensed professionals who act as members of local governments and provide services to local community residents. For professionals, having a "professional identity" has been found to be indispensable for performing their duties [1]. Research has shown that professional identity develops through the engagement in daily routines in the workplace [2] and its structure varies between occupational fields [3] [4]. According to Gregg and Magilvy, when nurses establish their professional identity, they refine their nursing practice [5]. As for PHNs in particular, they must base their professional activities on two professional identities: medical professional and local government servant. Moreover, PHNs' professional identity is shaped by the health-related problems they deal with [6]. In this sense, their professional identity probably has more a complex structure compared to other professions. Assuming this is the case, this factor might explain why PHNs have difficulties establishing their professional identity.

PHNs must establish their professional identity early on in order to deliver high quality public health services. Unfortunately, however, the structure of their professional identity is not fully understood. Therefore, this study aimed to examine the structure of PHNs' professional identity. Revealing this structure will contribute to improving PHNs' education and training.

\section{Methods}

\subsection{Definitions}

In this study, PHNs' "professional identity" was defined as an attitude in which a person self-identifies as a PHN, with an identity that shapes his/her ideas and values, facilitating steady development. The formulation of this definition was based on previous literature [2] [5] [7] [8] [9].

\subsection{Developing Draft Items Describing PHNs Professional Identity}

A set of draft question items was prepared based on the components of novice PHNs' professional identity defined by Kanefuji et al. [10]. This set of 21 items was developed by eight professionals: PHNs with a master's degree, PHNs with over 30 years of experience, and university teachers who trained PHNs. We also referred to existing scales for measuring nurses' professional identity [8] [11] [12] [13] [14]. Each question item was ranked on a 5-point scale from 1 (Disagree) to 5 (Agree), with higher scores indicating stronger professional identity. The draft question items were tested with six PHNs who were not involved in the development of the items. These pre-test participants provided information about the time taken to complete the questionnaire, the level of difficulty, and whether they felt that the wording of the questions conveyed PHNs' professional identity. 


\subsection{Participants and Method}

A questionnaire survey was conducted with 670 PHNs in A prefecture. Supervisor-PHNs who were singly appointed by their local governments were approached by telephone, and the purpose and method of the study was explained to them and their participation was requested. If a supervisor-PHN agreed to participate, the appropriate number of questionnaire sets was posted to him/her, each containing a briefing on the study aims and procedure, an envelope for returning the completed questionnaire, and the questionnaire form. Upon receiving the questionnaire sets, the supervisor-PHNs distributed them to all PHNs in their local government. Then, they completed the questionnaires and returned them using the envelopes provided. The survey took place from August to November 2014.

\subsection{Survey Content}

The questionnaire included questions on basic attributes, i.e., age, professional nursing experience, number of years as a PHN, occupational status of superior, and number of PHNs in the workplace. Additionally, it included the 21 questions on PHN professional identity, and Rosenberg's self-esteem scale. This self-esteem scale provides a measure of individuals' evaluation of their own worth; it contains 10 items answered on a 5-point scale, and its reliability and validity have been confirmed. Self-esteem has been found to provide a foundation for developing identity [2]. As such, it can be used to test the validity of a professional identity structure.

\subsection{Statistical Analysis}

First, basic demographic characteristics of the sample were obtained by summarizing the information on basic attributes. Subsequently, the responses to the 21 professional identity items were analyzed using exploratory factor analysis with the generalized least squares (GLS) and promax rotation techniques. Items with factor loadings $<0.4$ in this analysis were eliminated. To confirm the goodness-of-fit of the structural model derived from this analysis, a confirmatory factor analysis was performed. Factors were named based on the items they comprised. To test the reliability of the model, Cronbach's alpha was calculated for the whole model.

Subsequently, factor loadings of the professional identity items were treated as scores, and Spearman's coefficient for the relationship between self-esteem and professional identity scores was used to assess the validity of the model. The relationship between PHNs' professional identity and basic attributes was then analyzed using the Mann-Whitney test when the basic attribute variable had two levels, and the Kruskal-Wallis test when it had three or more levels. To test whether professional identity was correlated with years of experience [5], responses for years of experience were divided into three groups: $<5$ years (novice), 5 to $<25$ years (mid-level), and over 25 years (manager). All statistical analyses 
were conducted with SPSS 22.0 for Windows, and the significance threshold was set at $5 \%$

\subsection{Ethical Considerations}

The survey was anonymous, and returning the questionnaire indicated consent to participate in the study. The briefing detailed the study aim and procedures, the method of personal information protection, the fact that participation was entirely voluntary, and that the results will be published. The study was approved by the ethics committee of the Health Sciences Major of the Graduate School of Biomedical \& Health Sciences of Hiroshima University (July 15, 2014).

\section{Results}

A total of 670 questionnaires were distributed, and 350 of these were returned (return rate $=52.2 \%$ ). Questionnaires from respondents on a temporary assignment or with multiple questions unanswered were excluded, leaving 309 questionnaires for the final analysis (effective response rate $=88.3 \%$ ).

\subsection{Respondents' Characteristics}

Table 1 shows the respondents' characteristics. Regarding age, 20.7\% were in their $20 \mathrm{~s}, 20.4 \%$ in their $30 \mathrm{~s}, 27.7 \%$ in their 40 s, and $30.9 \%$ were 50 years or older. As for nursing experience, $30.9 \%$ had worked as a nurse before becoming a PHN. Regarding years as PHNs, $20.7 \%$ were novices, $46.5 \%$ mid-level, and $32.8 \%$ were managers; the average number of years of experience was $17.8 \pm 11.3$. Regarding status of superior, $46.8 \%$ worked under a PHN. As for the number

Table 1. Respondents' characteristics $(\mathrm{N}=309)$.

\begin{tabular}{|c|c|c|c|}
\hline Characteristics & & $\mathrm{n}$ & $\%$ \\
\hline \multirow{4}{*}{ Age } & $20 \mathrm{~s}$ & 66 & 21.4 \\
\hline & $30 \mathrm{~s}$ & 61 & 19.7 \\
\hline & $40 \mathrm{~s}$ & 87 & 28.2 \\
\hline & 50 years or older & 95 & 30.7 \\
\hline \multirow{2}{*}{ Experience of registered nurse } & Yes & 94 & 30.4 \\
\hline & No & 215 & 69.6 \\
\hline \multirow[t]{2}{*}{ Year of experience of PHNs } & $($ mean $\pm \mathrm{SD})$ & \multicolumn{2}{|c|}{$17.84 \pm 11.34$} \\
\hline & PHNs & 145 & 46.9 \\
\hline \multirow{2}{*}{ Supervisor's occupation } & Others & 164 & 53.1 \\
\hline & Less than 2 & 57 & 18.4 \\
\hline \multirow[t]{2}{*}{ Number of PHNs in the workplace } & $3-5$ & 58 & 18.8 \\
\hline & More than 6 & 194 & 62.8 \\
\hline Self-esteem score & $($ mean $\pm \mathrm{SD})$ & \multicolumn{2}{|c|}{$34.31 \pm 6.31$} \\
\hline
\end{tabular}

N: number, PHNs: Public Health Nurses, SD: Standard Deviation. 
of PHNs in the workplace, $18.5 \%$ were in workplaces with less than 2 PHNs, $18.8 \%$ with 3 to 5 , and $62.4 \%$ with 6 or more. The average self-esteem score was $34.3 \pm 6.31$.

\subsection{Professional Identity Structure}

\subsubsection{Factor Analysis}

The mean total score for the 21 professional identity items was $78.6 \pm 11.0$, with the score range being 37 to 103 . The mean scores for the individual items ranged from 2.87 to 4.30 . Floor effects were not observed, but four items $(2,3,10$, and 19) exhibited a ceiling effect (Table 2). The normality of the 21 item scores was tested with the Shapiro-Wilk normality test and could not be confirmed; thus, Spearman's correlation coefficient was used. There were strong positive correlations of $>0.7$ between items 1 and $2(\rho=0.700), 1$ and $3(\rho=0.701), 2$ and 3 ( $\rho=$ $0.789)$, and 15 and $16(\rho=0.713)$. After comparing the wording of these items

Table 2. Scores on PHN professional identity items $(\mathrm{N}=309)$.

\begin{tabular}{|c|c|c|c|}
\hline No. & Item & Mean & SD \\
\hline 1 & I feel pride in working as a $\mathrm{PHN}$ & 4.13 & 0.85 \\
\hline 2 & I think that a PHN's work is interesting & 4.23 & 0.80 \\
\hline 3 & I think that a PHN's work is rewarding & 4.30 & 0.77 \\
\hline 4 & I feel that PHNs have unique abilities & 3.89 & 0.86 \\
\hline 5 & I am suited to working as a PHN & 3.34 & 0.84 \\
\hline 6 & I have my own ideas about PHNs & 3.70 & 0.80 \\
\hline 7 & I have a PHN model & 3.71 & 0.91 \\
\hline 8 & I am always mindful of my role as a $\mathrm{PHN}^{*}$ & 3.76 & 0.78 \\
\hline 9 & I have confidence in my abilities as a PHN & 2.87 & 0.90 \\
\hline 10 & I want other professionals to understand the work that PHNs do & 4.32 & 0.76 \\
\hline 11 & I think that PHNs play a central role in inter-professional collaboration* & 3.88 & 0.84 \\
\hline 12 & $\begin{array}{l}\text { I can incorporate the needs/opinions of residents and } \\
\text { organizations into administrative undertakings }\end{array}$ & 3.23 & 0.88 \\
\hline 13 & Feedback from others contributes to my self-confidence & 3.57 & 0.83 \\
\hline 14 & I am depended on by the residents in my charge & 3.13 & 0.75 \\
\hline 15 & I am developing as a human being through my work ${ }^{*}$ & 4.06 & 0.74 \\
\hline 16 & I am developing as a PHN through my work & 3.93 & 0.77 \\
\hline 17 & My work as a PHN influences my way of life & 3.98 & 0.82 \\
\hline 18 & My experience is useful to my junior colleagues & 3.23 & 0.91 \\
\hline 19 & I want to develop further as a PHN & 4.24 & 0.77 \\
\hline 20 & I have goals for developing as a $\mathrm{PHN}^{\star}$ & 3.57 & 0.89 \\
\hline 21 & I make self-driven efforts to develop as a PHN & 3.55 & 0.81 \\
\hline
\end{tabular}

N: number, PHN: public health nurse; SD: Standard deviation; Items marked with * showed a ceiling effect. 
with that of other items, 2 of the items ( 3 and 15) were removed from the analysis, leaving 19 items. Respondents were divided into 2 groups: those with low total scores ( 85 respondents, $27.5 \%$ of the sample) and those with high total scores (75 respondents, $24.3 \%$ of the sample), and a good-poor analysis was performed on the two groups. This confirmed that the scores on all items were consistent with the total scores. An item-total correlation analysis was then conducted, and I-T correlation values between 0.472 and 0.700 were obtained.

\subsubsection{Factor Structure}

An exploratory factor analysis with the 19 items was conducted using the principal factor method to estimate the number of factors, starting with four factors. After investigating the normality of the total scores on the 19 items, Spearman's correlation coefficient was used. Since all items were positively correlated with each other, a factor analysis using promax rotation and GLS was conducted. Items with factor loadings $<0.4$ were excluded and the analysis repeated, which yielded 11 items categorized into three factors (Table 3). Cronbach's alpha for the whole set of items was 0.87 .

The factor structure of the hypothetical model derived from the above analysis was the subjected to a confirmatory factor analysis, with goodness-of-fit indices as follows: goodness-of-fit index $=0.95$, adjusted goodness-of-fit index $=0.92$, root mean square error of approximation $=0.59$, and Akaike's information criterion $=134.5$. All these values were at an acceptable level, denoting that the model's goodness-of-fit was within a statistically acceptable range (Figure 1).

Table 3. Professional identity structure $(\mathrm{N}=309)$.

\begin{tabular}{|c|c|c|c|c|}
\hline \multirow{2}{*}{\multicolumn{2}{|c|}{ Factor(Item) }} & \multicolumn{3}{|c|}{ Exploratory Factor analysis } \\
\hline & & Factor 1 & Factor 2 & Factor 3 \\
\hline \multicolumn{5}{|c|}{ (4 items) $\alpha=0.803$} \\
\hline 20 & I have goals for developing as a $\mathrm{PHN}^{*}$ & 0.971 & 0.012 & -0.062 \\
\hline 19 & I want to develop further as a PHN & 0.698 & -0.199 & 0.159 \\
\hline 21 & I make self-driven efforts to develop as a PHN & 0.588 & 0.209 & -0.027 \\
\hline 7 & I have a model PHN & 0.408 & 0.072 & 0.202 \\
\hline Factor 2 & \multicolumn{4}{|l|}{ (4 items) $\alpha=0.781$} \\
\hline 18 & My experience is useful to my junior colleagues & -0.031 & 0.745 & -0.014 \\
\hline 9 & I have confidence in my abilities as a PHN & -0.087 & 0.712 & 0.088 \\
\hline 12 & $\begin{array}{l}\text { I can incorporate the needs/opinions of residents and } \\
\text { organizations into administrative undertakings }\end{array}$ & 0.137 & 0.672 & -0.134 \\
\hline 14 & I am depended on by the residents in my charge & -0.042 & 0.601 & 0.170 \\
\hline Factor 3 & (3 items) $\alpha=0.821$ & & & \\
\hline 1 & I feel pride in working as a $\mathrm{PHN}$ & -0.019 & -0.031 & 0.986 \\
\hline 2 & I think that a PHN's work is interesting & 0.085 & 0.067 & 0.686 \\
\hline \multirow[t]{4}{*}{4} & I feel that PHNs have unique abilities & 0.156 & 0.047 & 0.470 \\
\hline & Spearman's correlation 1 & 1.000 & & \\
\hline & 2 & 0.477 & 1.000 & \\
\hline & Cronbach's alpha $=0.867$ & 0.592 & 0.533 & 1.000 \\
\hline
\end{tabular}

$\mathrm{N}$ : number, factor analysis using promax rotation and GLS. 


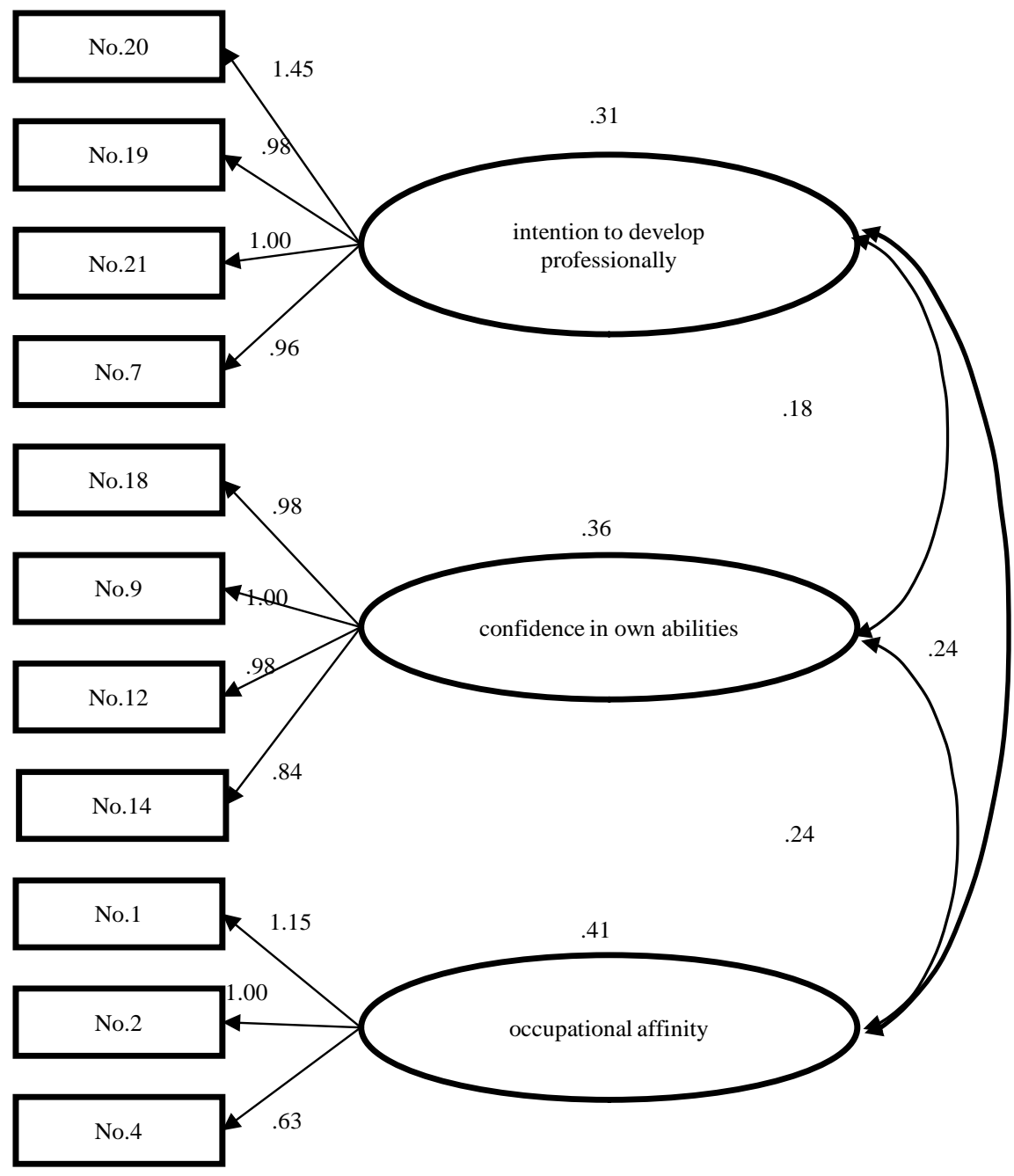

Figure 1. Confirmatory factor analysis $(\mathrm{N}=309)$.

The item indicated by the number is the same as Table 2 .

\subsubsection{Factor Naming}

The four items making up Factor 1 described a PHN who envisages an ideal PHN model and goals, and strives toward such an ideal; accordingly, this factor was named "intention to develop professionally." The four items making up Factor 2 described self-confidence in one's skills as a PHN, and were interpreted as obtaining the trust of residents and believing he/she could incorporate residents' needs into his/her services/strategies. Accordingly, this factor was named "confidence in own abilities." Factor 3 comprised three items, describing pride in and affinity with job, which refer to PHNs conducting their activities believing that their job is interesting and that they have abilities specific to PHNs, contributing to a sense of professional pride. Accordingly, this factor was named "occupational affinity."

\subsubsection{Validity}

Spearman's correlation coefficient between self-esteem scores and professional 
identity total scores was $\rho=0.384$. The coefficients for the correlation of self-esteem with each of the three factors, i.e., "intention to develop professionally", "confidence in own abilities," and "occupational affinity," were $\rho=0.191$, $\rho=0.386$, and $\rho=0.353$, respectively.

\subsection{Basic Attributes Correlated with Professional Identity}

Table 4 shows the relationship between basic attributes and professional identity. The job type of PHNs' superior did not have a significant impact on professional identity. Scores on the 11 professional identity items tended to be higher among respondents who were older, had no experience in nursing, and had more years of experience as a PHN. "Intention to develop professionally" was not affected by any of the basic attributes, while "confidence in own abilities" varied significantly by age and years of experience. "Occupational affinity" was affected by age, number of PHNs in the workplace and years of experience.

Table 4. Relationship between basic attributes and professional identity $(\mathrm{N}=309)$.

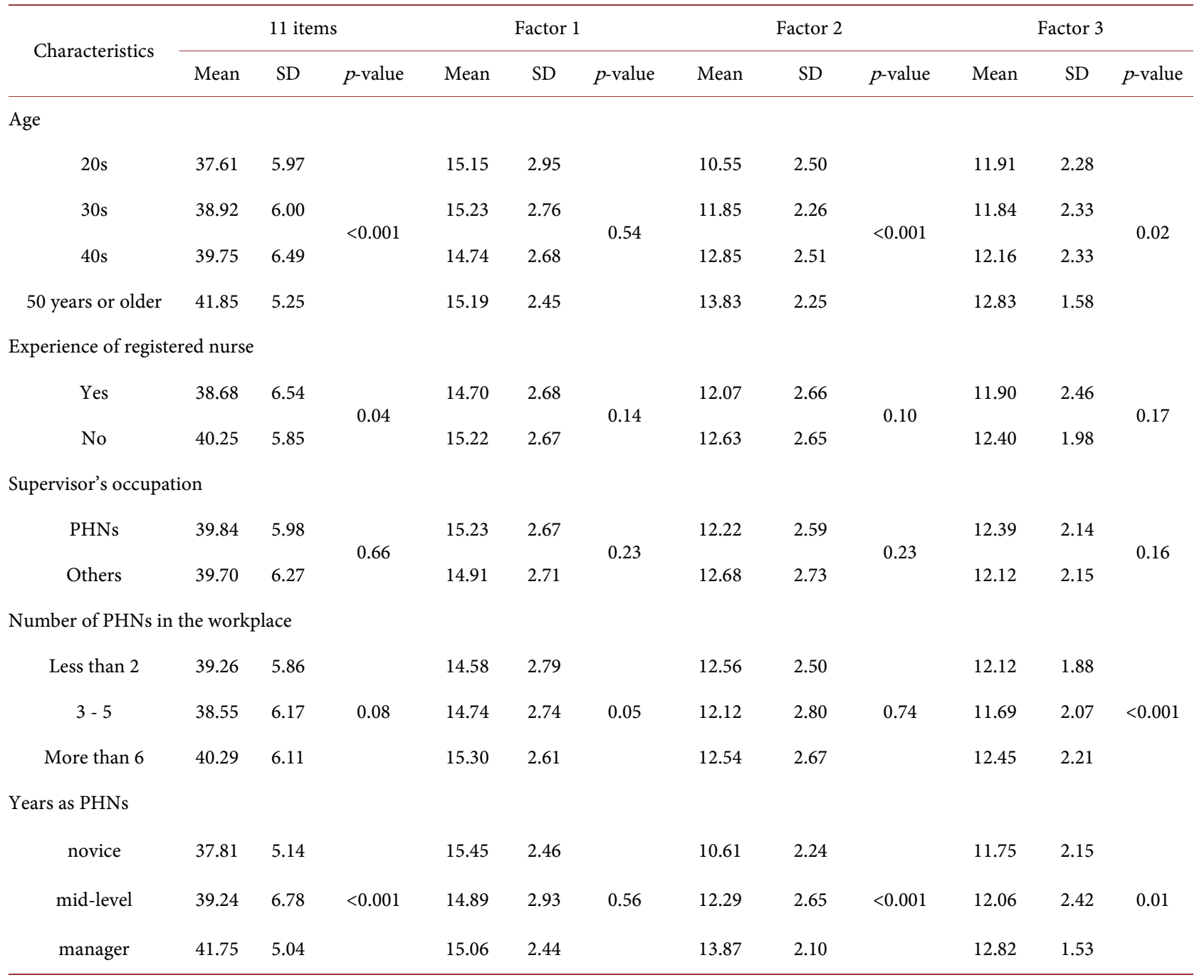

SD: Standard deviation, Mann-Whitney test and Kruskal-Wallis test. 


\section{Discussion}

The structure of PHNs professional identity was found to consist of three factors: "intention to develop professionally," "confidence in own abilities," and "professional affinity." Of these, "intention to develop professionally" does not feature in the previous literature, and thus represents a distinctive aspect of professional identity identified in this study. According to Maeda et al., for professionals to establish their professional identity, they must first actively assume the responsibility to continually learn about their profession [15]. It was found that "intention to develop professionally" was not significantly affected by years of experience, which implies that PHNs are a professional group that make continuous self-driven efforts to refine their skills. Individuals are initially motivated to learn when they observe model behavior in others [16], and colleagues with leadership abilities can inspire younger employees to establish their professional identity [17]. Presumably, therefore, PHNs develop a clear vision of the PHN model as they observe the behavior of and interact with other PHNs around them, which then motivates them to develop themselves as PHNs. A desire to develop is a critical prerequisite for maturing as a professional [18]. Thus, "intention to develop professionally" is a key factor of the structure of PHNs' professional identity.

Scores for "confidence in own abilities" were positively correlated with years of PHN experience, which is consistent with the literature [19]. Fujii et al. reported a positive correlation between years of experience in nursing and pride in one's nursing skills [12], and this phenomenon is evident in PHNs' professional identity too. Matsuo et al. found that the more novel one's experiences are, the more they encourage one to develop [20], and Cox reported that the experience of having one's behavior eliciting direct responses from others significantly contributed to self-confidence [21]. PHNs serve local residents by engaging in the area's health issues, for which they must employ innovative strategies and work with other professionals. As such, PHNs have plenty of novel experiences and frequently receive positive feedback from residents. Thus, PHNs' professional identity develops as they increasingly accumulate experiences of direct encounters with residents.

PHNs' increase their "professional affinity" by interacting with various individuals they encounter in their work. Dahl et al. noted that PHNs established their professional identity by reflecting with fellow PHNs [22]. Inter-professional encounters also help PHNs establish their professional identity by prompting them to appreciate their role [23]. Reflecting on past experiences provides professionals with new learning opportunities that elevate their professional awareness [24]. Thus, "professional affinity" develops through the interaction with fellow PHNs and other professionals.

The three factors and 11 items derived from the exploratory factor analysis exhibited strong correlations and a high Cronbach's alpha coefficient, and the confirmatory factor analysis indicated that the model fell within a statistically 
acceptable range. The structure can also be explained with reference to actual PHN practice, denoting its validity as a structure of PHN professional identity.

\section{Conclusion}

The results of this study suggest that PHNs' professional identity has a threefactor structure: "intention to develop professionally," "confidence in own abilities," and "professional affinity."

\section{Acknowledgements}

I would like to express my gratitude to all the PHNs in the Prefecture who participated in the study. This study was supported by the Japan Society for the Promotion of Science (JSPS: 24792556). There are no conflicts of interest to declare.

\section{References}

[1] Fagermoen, M.S. (1997) Professional Identity: Values Embedded in Meaningful Nursing Practice. Journal of Advanced Nursing, 25, 434-441. https://doi.org/10.1046/j.1365-2648.1997.1997025434.x

[2] Ericsson, E.H. (2011) Identity and the Life Cycle. Seishin Shobo, Tokyo.

[3] Yamamoto, Y., Nagatani, R., Fujii, K., et al. (2003) A Study on Differences in Identity between General Hospital and Rehabilitation Medical Center Nurses. The Publication for Studies in Ibaraki Prefectural University of Health Sciences, 8, 89-98.

[4] Yamaguchi, Y. and Momose, Y. (2013) Relationship between Professional Identity Characteristics and Individual Traits in Visiting Nurses. Journal of Japan Academy of Home Care, 17, 49-58.

[5] Gregg, M.F. and Magilvy, J.K. (2001) Professional Identity of Japanese Nurses: Bonding into Nursing. Nursing and Health Sciences, 3, 47-55. https://doi.org/10.1046/j.1442-2018.2001.00070.x

[6] Öhlén, J. and Segesten, K. (1998) The Professional Identity of the Nurse: Concept Analysis and Development. Journal of Advanced Nursing, 28, 720-727. https://doi.org/10.1046/j.1365-2648.1998.00704.x

[7] Johnson, M., Cowin, L.S., Wilson, I. and Young, H. (2012) Professional Identity and Nursing: Contemporary Theoretical Developments and Future Research Challenges. International Nursing Review, 59, 562-569. https://doi.org/10.1111/j.1466-7657.2012.01013.x

[8] Negishi, K., Asahara, K. and Yanai, H. (2010) Developing a Professional Identity Scale: Identifying Factors Related to Professional Identity of Government-Employed Public Health Nurses. Japanese Journal of Public Health, 57, 27-38.

[9] Ohlen, J. and Segesten, K. (1993) Professionalization-Theoretical Analysis of the Implications for Nursing Practice. Scandinavian Journal of Caring Sciences, 8, 3-8. https://doi.org/10.1111/j.1471-6712.1994.tb00215.x

[10] Kanefuji, A., Nakatani, H. and Oeki, M. (2016) Professional Identity Components of Novice Public Health Nurses Working for Local Government Agencies. Journal of Health Sciences Hiroshima University, 14, 1-10.

[11] Sasaki, M. and Hariu, T. (2006) Development of the Professional Identity Scale for Nurses (PISN). Japan Journal of Nursing Science, 26, 34-41.

https://doi.org/10.5630/jans.26.1_34 
[12] Fujii, K., Nonomura, N., Suzuki, S., et al. (2002) An Analysis of the Vocational Identity of Medical Sciences Students. The Publication for Studies in Ibaraki Prefectural University of Health Sciences, 7, 131-142.

[13] Hatano, K. and Onodera, T. (1993) Professional Identity of Student Nurses and Graduates. Journal of Japan Society of Nursing Research, 16, 21-27.

[14] Iwai, K., sawada, Y., Nonomura, N., et al. (2001) Process of Developing Professional Identity of Nurse. The Publication for Studies in Ibaraki Prefectural University of Health Sciences, 6, 57-67.

[15] Maede, T. (2009) Requirements for Studying Vocational Identity Formation of Profession. The Society for Psychological Studies Department of Humanities Kansai University, 3, 5-14.

[16] Bandura, A., Blanchard, E. and Ritter, B. (1969) Relative Efficacy of Desensitization and Modeling Approaches for Inducing Behavioral, Affective, and Attitudinal Changes. Journal of Personality and Social Psychology, 13, 173-199. https://doi.org/10.1037/h0028276

[17] Masaki, S. and Okada, M. (2010) Influence of Workplace Relatedness on Vocational Identity Formation in Early Career. Japanese Association of Industrial/ Organizational Psychology Journal, 24, 29-42.

[18] Matsuo, M. (2007) Learning from Experience: The Process of Becoming a Professional. Nippon Academy of Management, 55, 21-24.

[19] Tanaka, S., Ayukawa, M., Yamaguchi, A., et al. (2014) Survey Report on Professional Identity of Nursing Students. Journal of Nursing Health Science Research, 15, 101-107.

[20] Matsuo, M. (2011) Learning from Experience. DAIAMOND, Inc., Tokyo.

[21] Cox, D.W. (1984) Experiental Learning-Experience as the Source of Learning and Development-Kolb, DA. Journal of College Student Personnel, 25, 481-482.

[22] Dahl, B.M., Clancy, A. and Andrews, T. (2014) The Meaning of Ethically Charged Encounters and Their Possible Influence on Professional Identity in Norwegian Public Health Nursing: A Phenomenological Hermeneutic Study. Scandinavian Journal of Caring Sciences, 28, 600-608. https://doi.org/10.1111/scs.12089

[23] King, N. and Ross, A. (2003) Professional Identities and Interprofessional Relations: Evaluation of Collaborative Community Schemes. Social Work in Health Care, 38, 51-72. https://doi.org/10.1300/J010v38n02_03

[24] Donald, A.S. (1983) The Reflective Practitioner: How Professionals Think in Action. Basic Books, New York. 